\title{
Affective Disorders in Epilepsies: a Neuropsychiatric Review
}

\author{
DAVID C. TAYLOR
}

University of Manchester, Jesson House (R.M.C.H.), 78 Manchester Road, Swinton, Manchester M27 $1 F G, U . K$.

\begin{abstract}
Psychiatry and neurology are well-established as separate disciplines and they may view an issue of mutual concern, such as affective disorder in people with epilepsy, from such different premises that the important synthesis of behavioural neurology, or neuropsychiatry, will be made ineffective. Nosological problems stemming from the use of diagnostic manuals are discussed and revealed in case reports. Reports of affective disorder in persons with brain disorders are relatively rare, possibly as a consequence of nosological problems which stem from a maintenance of a tradition of "functional" disorder. New cases of bipolar disorder and organic mania are given with commentary on the preponderant lateralization of cerebral dysfunction to the right cerebral hemisphere in manic cases.
\end{abstract}

\section{Neuropsychiatry and Affective Disorder}

The basic materials of psychiatry are the subjective experiences of people and their behaviour in a social context. Many useful discourses can be maintained about these without reference to cerebral disorder and without recourse to explanations in those terms. A grief reaction, albeit severe, might thus be explicable in terms of a commonplace, appropriate response to loss to which might be added further explanations in terms of ambivalence about the lost object and a sensitization by previous experience of loss. The evident changes in vitality, interest, concentration and sleep suggest that the subjective experiences are sustained by the action of some cerebral system which is acting differently from usual. Through biotechnology we might have some ideas about that system, but it would be inappropriate in explaining the experience of grief which remains most understandable as a loss from the outside world.

The basic materials of neurology are reports of, or physical evidence of, dysfunctions which are adduced to concern the nervous system. Its explanations do not concern empathy or subjectivity but refer directly or indirectly to interference with the propagation of nervous impulses. The difference between neurology and psychiatry might be typified by the difference between being unable, as opposed to being unwilling, to speak. The sorts of things which are regarded as explanatory of speechlessness will also differ, not just because they explain different things, but different sorts of things.

Neuropsychiatry grows both from psychiatry and from neurology which approach it from different premises, to explain those aspects of subjective $0953-4180 / 89 / 020049+20 \$ 3.50 / 0$

(C) 1989 CNS (Glinical Neuroscience) Publishers 
experience and behaviour which are beyond empathy, beyond the understandable, beyond the broad fringes of the normal. The neurologist is interested in the subjective and behavioural aspects of neurological dysfunction; the psychiatrist in whether disorder in neurological systems might underlie abnormal subjective experience. These are not precisely the same concerns.

Seizures can be provoked in all brains. Their spontaneous occurrence is unusual and suggests neurological dysfunction. It is reasonable to ask whether there is other evidence suggestive of neurological dysfunction even if that evidence is subjective; even if subjective evidence is difficult to codify, difficult to classify, such as a change of mood. Some seizures are associated with structural abnormalities of brain, these may occupy various loci, provoke predictable types of seizure, promote particular types of subjective experience and behaviour. Perhaps these may help inform us about the sorts of cerebral systems, which support human behaviour, that are used for ordinary feelings or even intense feelings such as grief.

Confounding our capacity to derive such information is the genetic uniqueness of the individual, variability in development and experience; and further variabilities are imposed by compensation occurring in the brain for those very lesions which appear to be consistent markers.

Nineteenth century alienists (and others since) looked for precise correspondence between particular cerebral disorder and consequent psychopathology; or for a particular brain disorder to conform to their psychopathological entities. They were disappointed. The psychopathological entities are artefacts even when they are rigidly codified and generally agreed. For example, the British in Africa delineated very precisely the territories they commanded and named them clearly. But these artefacts flew in the face of geographical, climatic, racial and linguistic unities so that all sorts of inner consistencies and verities were lost and the creation of these convenient administrative boundaries has caused problems.

Similarly with convenient nosological entities; the cerebral systems governing mood, or emotion, or certain cognitive capacities may not be served within the sorts of dichotomies by which we have lately chosen to analyse them, or by the sorts of entities which we have created to interrogate them. If evidence about "affective disorders" in "epilepsies" is crude, variable and inconsistent, it is not surprising.

In this paper some of the studies of affective disorder in people with epilepsy are reviewed from a neuropsychiatric perspective, drawing attention to nosological issues which might confound them and make better studies difficult. Two bipolar patients are described. The potential value of studying organic mania is illustrated with newly described personal cases and with reference to recently presented cases. Young people with epilepsy and hypomania seem to differ remarkably little phenomenologically or nosologically from children with the organic hyperkinetic syndrome. Certain contributions from the series of patients with temporal lobe epilepsy operated upon by Murray Falconer are mentioned. 


\section{The Nosology of Affective Disorders}

DSM III (American Psychiatric Association, 1980) characterizes affective disorder into Manic episode; Major depressive episode; Bipolar disorder; Cyclothymic disorder; Dysthymic disorder and Atypical depression. But these diagnoses seem to be precluded for people with epilepsy by the presence of Organic Mental Disorders which depend upon "evidence from either physical examination, medical laboratory tests, or the history of a specific organic factor that is judged to be etiologically related to the disturbance".

These diagnostic constraints were intended to be helpful, to enable psychiatrists to achieve some conformity and distinguish "functional" from "organic" mental disorder, a most important distinction. But they create great difficulties for psychiatrists and neurologists working at the interface of the subjects (Woods et al., 1986). Suffering from epilepsy may make any accompanying mental disorder "organic" in these terms, and the better the psychiatrist searches for neurological signs and neurodiagnostic test changes, the less the "functional" category can be substantiated. Looking alternatively in DSM III to Organic Affective Syndrome does not much help as "there is (to be) no significant loss of intellectual abilities as in Dementia"; and "no predominant delusions or hallucinations". Since these do occur in people with epilepsy it becomes difficult to write about the affective disorders in epilepsy within the constraints of the DSM terminologies.

The most systematic, sustained, and complex account of affective disorder, whether "symptomatic or endogenous", as he puts it, is that of Flor-Henry (1983a, 1983b, 1983c, 1985a, 1985b). He has developed, from an original study in the psychiatry of epilepsy, on complex neurophysiological and neuropsychological lines, a highly sophisticated, not to say abstruse, system of explanation of affective disorders. His schema includes consideration of most of the factors concerning affective disorder which are wellestablished in the minds of psychiatrists today, such as developmental, experiential, neuroendocrine, neurotransmitter and genetic factors.

Whatever the specific links between depression and epilepsy, Pond (1957) reminded us that people with epilepsy are at least no less prone to the whole gamut of psychiatric disorder than any other collection of persons. The DSM III seems to deprive people with epilepsy of those possibilities and is potentially stigmatizing as well as unhelpful.

Studying affective disorder in epilepsy is interesting because it may:

(a) illuminate the general problem of mood related disorders;

(b) prove that the problem for people with epilepsy is noticeably different in quality or quantity;

(c) or that there is an identifiable subset of persons among epileptics who are particularly prone or who show unusual symptoms which provide interesting correlations with their development and life experience or with their abnormal neurophysiology or specific structural changes in the brain. 


\section{Depression}

In the disorder psychiatrists call depression, it is mood which is characteristically "depressed" often along with certain vegetative functions. The experience is most easily understood empathically from the sorts of states which accompany serious loss, especially bereavement. Describing their prevailing mood, say on the GHQ (General Health Questionnaire: Goldberg, 1972) about $20 \%$ of the population will respond in a way similar to people who actually seek psychiatric help. Severity is assessed in terms of duration, psychomotor retardation, severe vegetative effects, development of delusions, severe dysphoria, guilt and suicidal ideas. Theories of the aetiology of depression (Rutter and Garmezy, 1983) provide that genetic, neuroendocrine, cognitive and psychological factors need to be considered. There is no doubt of the genetic component of recurrent depressive and manic-depressive psychosis (Slater, 1936). The neuroendocrine effects concern both a priming and sexing of brain, as is suggested by the excessive female vulnerability to depression and by the subsequent events of puberty from which point the incidence of depressive states vastly increases. The cognitive component (Rutter and Garmezy, 1983), is that "they acquire cognitive schemata involving a devaluation of themselves and their experiences together with a hopelessness about the future". This mental set is widely reported in the chronically sick (Schmale, 1958). Stresses which precede mental illnesses are created by undesired and uncontrollable "life events". Psychoanalytic views concern loss in particular, loss of wholeness, loss of "things as they were" and even loss of "things as they might have been".

People with epilepsy do suffer excessively from stressors and losses (Dodrill et al., 1984a, 1984b) so as a group, irrespective of any effect of brain disorder, they would have an increased risk of affective disorder. The presence of brain disorder greatly increases the risk of psychiatric disorder though more specific correlations are much more difficult to prove.

Systematic studies of affective disorders in people with epilepsy are relatively sparse. A recent comprehensive study of depression in epilepsy published, significantly, in Archives of Neurology (Mendez et al., 1986) presents a two-part project drawing first on questionnaire responses from persons who were using vocational services for the disabled. Of 503 epileptics who received questionnaires 175 or $35 \%$ responded; of 186 non-epileptics 70 or $38 \%$ were returned. If these persons' reasons for not responding were related to a lack of psychiatric disorder it would seriously affect overall rates. Even so, controls were significantly less prone than epileptics to answer positively to 13 of 50 behavioural items, even though there were few items which discriminated them in degree of psychosocial difficulty. Suicide attempts and hopelessness about the future were the most discriminating "depressive" items; often wishing they were dead, and feeling unhappy with themselves were also significantly different. Surprisingly, these facts emerged in a population of people with epilepsy, $40.7 \%$ of whom had attacks no more than once a year, or even less, and a further $29.3 \%$ of whom 
had no more than monthly attacks. In this part of the study males and females were equally represented.

In the second part the characteristics of 20 depressed epileptic patients were compared with 20 depressed non-epileptic patients all admitted to the Brentwood VA hospital. Unlike typical depressives these patients were predominantly males. Depressed epileptics differed in psychopathology from non-epileptic depressed patients.

A discriminant analysis showed that chronic dysthymia, lack of "neurotic" traits; and periods of agitated peri-ictal psychotic behaviour correctly predicted $93 \%$ of depressed epileptics. It is evident that several characteristics seen "more in epileptics" in Table 1, even though set in the context of many symptoms of depression, are not dissimilar to those given in DSM III under Organic Personality Syndrome which lists: (i) emotional lability, temper outbursts and sudden crying, (ii) impairment of impulse control, (iii) marked apathy and indifference, (iv) suspiciousness and paranoid ideation. This suggests that an "organic" flavour is given to the affective disturbance of people with epilepsy, as it has been said previously to be given to the schizophrenia-like psychosis of epilepsy. In particular, these psychopathological elements might be consonant with the finding of a bias towards left brain foci in 11 of the 15 (of 20) epileptic patients with lateralized, principally temporal, EEG foci. The Mendez et al. results are consistent with those of d'Elia and Perris (1973) results and with a smaller but detailed study by Perini and Mendius (1984) using similar patient sources. That study, however, was unmatched sex by side so that of 8 right-sided patients 7 were male, and 5 of 6 females used had left foci. These, sex by side, characteristics of samples of complex partial seizures are germane in many aspects of their psychopathology (Taylor, 1981). Scott (1985) drew renewed attention to the fact that once much interested psychiatrists (Rey et al., 1949), that symptomatic epilepsy is more likely to arise from left than from right brain lesions, and that left-sided EEG changes predominate in very large samples of patients with temporal lobe epilepsy. Hence they would tend to predominate in samples drawn for psychiatric analysis too.

In their review, Robertson and Trimble (1983) mention the many studies of epileptic subjects using the MMPI and finding increases in the depression scores, some of which have revealed particular increases in patients with CPS, especially in older patients. Depressive and anxiety/ depressive states are frequently mentioned in epileptic people who are

TABLE 1. Characteristics of depressed epileptic patients compared with depressed non-epileptic patients

\begin{tabular}{lll}
\hline More in Epileptics & Same & More in Non-Epileptics \\
Psychotic behaviour & Neurovegetative signs & Self pity/low self image \\
Abnormal affect & Psychomotor retardation & Brooding/Rumination \\
Humourlessness/Sobriety & Prior suicide attempts & Guilt feelings \\
Irritable/Emotional & & Somatization \\
Paranoid/Suspicious & & Anxiety \\
Chronic dysthymia & & Hopelessness/Helplessness \\
\hline
\end{tabular}

(Mendez et al., 1986) 
admitted to psychiatric hospitals. Trimble and Perez (1980) examined 281 patients admitted to an epilepsy centre for evaluation of their seizures or rehabilitation using a valid questionnaire procedure and also found raised levels of anxiety and depression, as did Kogeorgos et al. (1982) in neurological outpatients. Rates were about double what might be found in the ordinary population.

\section{Bipolar Affective Disorder}

Bipolar disorder (DSM III) requires concurrent or consecutive evidence of both depressive and manic symptomatology. Even though studies of depression and epilepsy are sparse, detailed reports of bipolar illness are even rarer. Mendez et al. (1986) mention 2 cases, Flor-Henry (1969) mentioned 9 in his report on 50 psychotic patients, this covering depressive patients too.

The problem of category priority in making diagnostic statements is well typified by a patient drawn from Taylor (1972).

No. 76

A bank clerk, he was aged 31 at the time of operation. He was a British subject born in Egypt. His mother was alive but his father, an alcoholic, died when the patient was aged 11 .

His birth was prolonged and difficult. At the age of 2 years nocturnal episodes were observed in which he would swallow, retch, and smack his lips for about 2 minutes; nocturnal grand mal started at 15 years.

At 23 his wife observed attacks by day if he fell asleep, and also nocturnal attacks. She described him as a violent morose man, very much feared by his children. Aged 27 he had attempted suicide.

He came to London with his family aged 28 but his wife left him because of his repeated assaults. He returned to the Lebanon to seek her but later returned alone to London to work in a bank where he forged a cheque. He was committed to prison for a year. On his discharge he had an acute psychotic episode in which he became resistive, postured, prayed in Arabic, and refused food. Recovery was immediate following one single electro-shock. One year prior to operation his wife rejoined him, unaware of the interim history.

In the Unit before surgery he developed a religious psychosis. Over a period of days, he became restless, took up an opisthotonic posture, closed his eyes and prayed aloud in Arabic, and complained of feeling a strange rushing in his ears. He was resistive and unmanageable. His wife described him as a liar and a cheat, a thoughtless, brutal, offensive animal, extremely aggressive, subject to ugly moods in which he would throw things about and hit the children.

EEGs revealed abnormal activity confined to the left temporal area. Psychological tests revealed VIQ 109, PIQ 95. On his recovery from the acute psychotic episode, left temporal lobectomy was undertaken and mesial temporal sclerosis was found. Following operation he was free of epileptic attacks and auras. Gradually his behaviour at home improved though he was subject to occasional bouts of hypochondriacal rumination and to moodiness. One year after surgery his $\mathrm{VIQ}=110, \mathrm{PIQ}=121$. He returned to his post as a bank clerk and gained regular promotion.

At follow-up 48 months after his operation, there was no abnormality in his 
mental state. His wife said that the ugly moods had disappeared, that he was no longer subject to violence, and that he was appreciated and liked at his job. Occasionally he would develop a hypochondriacal complaint but these generally disappeared if they were firmly and sympathetically handled.

A few months after that follow-up interview he became mildly hypomanic for a period of about 2 months, following which he became severely depressed for 10 days and required hospital admission. Not until after the paper was written did his manic-depressive disorder become apparent. During the course of his subsequent major mood swings various of the more disagreeable and socially problematic aspects of his personality emerged. What psychiatric diagnosis was the most important? Does one diagnosis preclude another? At which point in time should it be made?

One possible marker of changes in cerebral functioning was his fluctuating Performance IQ (95-121) as against his fixed Verbal IQ (109-110).

A further case illustrates manic-depressive mood swings which emerged at puberty out of a previously well-established depressive disorder to culminate in suicide without any evidence for personality disorder or other psychiatric diagnosis:

\section{Manic-Depressive-Bipolar Disorder}

\section{Patient 188}

He was 19 at the time of his right temporal lobectomy. The lesion was a calcifying haemangioma.

Third born of three children to a comfortably placed rural family, his birth and early development were normal. At 5 he became delirious for several days while suffering mumps and measles together. His performance at school belied his superior intelligence (W.B.I. on admission showed V.144 and P.128). From the age of 11 , he experienced disturbing episodic dream states, reminiscence, déjà vû. These intensified with low moods. Disappointed over a Latin test aged 12, he attempted suicide with aspirin. At 14 he suffered an adenoviral encephalitis and lost 3 months from school. The aura experiences became richer and intensified, feelings in the stomach, foul tastes, a "sensation of turquoise water covering me from head to foot". Very stern self-control could reduce their frequency.

After a grand mal seizure when aged 16, his mood worsened and he experienced unreality and depression. Several anticonvulsants failed to alter his seizures. He performed very poorly in school leaving exams. Treatment for his depression included ECT and drugs but mood swings continued; in episodes of elation he would work furiously, change jobs then, depressed, he would give up, retire to bed and sleep up to 18 hours a day. Another suicide attempt with codeine had serious intent but he changed his mind. When hypomanic he was over-friendly, garrulous, aggressive and meticulously neat. His need for sleep was diminished.

For eight months after surgery the fits ceased but the mood swings continued. One evening he spoke to his psychiatrist at 7 p.m. and to his father at 11.30 p.m. They both thought him well. When called, as requested at 6.20 a.m., he was dead. He had consumed a huge quantity of drugs which he had hoarded over a long period of time. 
This patient also showed a substantial Verbal/Performance discrepancy. Lewis et al. (1984) reported "psychomotor symptoms" in non-epileptic patients with bipolar illnesses. She observed lapses of contact with reality; loss of memory; unprovoked anxiety; episodes of déjà vû; depersonalization; and regarded them as "psychomotor phenomena" and suggested that they raise intriguing theoretical questions about the neurophysiology of bipolar illness. Mukherjee et al. (1984) found that one-third of their 75 patients with Bipolar disorder showed minor neurological signs (graphaesthesia and facehand tests). There were 31 males and 44 females in the sample. They were carefully neurologically screened. No mention is made of epilepsy or a history of epilepsy. The authors attribute the development of signs to chronic neuroleptic ingestion.

By contrast, in their study of 1227 inpatients, Johnstone et al. (1985) found 47 patients who fulfilled the St. Louis criteria for primary affective illness of whom 5 died and 13 were discharged before the detailed study. Of the remaining 29, 25 were female and 4 were male; 4 were depressed only and 2 suffered only manic episodes. Patients were assessed for their neurological status, cognitive capacity, and their mental state. The authors could not attribute their abnormality to neuroleptic medication. Three patients had a history of fits. Their social behaviour and their activity were more impaired than the other patients. This study of "a functional psychosis" reveals a $12 \%$ history of epilepsy. These large studies of manicdepressive illness reveal the usual bias towards female predominance in the populations and bring into question the reliability of those studies of affective disorder where the sample of patients is dominated by males. It also seems likely that patients with epilepsy who have manic-depressive illness are usually left out of studies of manic-depressive illness for the sorts of reasons touched on in the introduction.

\section{Hypomania and Mania}

For the purpose of understanding brain/behavioural relationships there would be distinct advantages to the study of mania and hypomania and epilepsy. Hypomania accounts for only about $10-15 \%$ of affective illness. Rarity should improve diagnostic precision. Unlike depressed affect which might be experienced by most people and prove uncomfortable to some, mild degrees of elated mood are unlikely to be seen by doctors. Treated hypomania is thus more likely to be severe and distinctly separable from situations or reactive moodiness.

Krauthammer and Klerman's (1978) paper on Secondary Mania has provided a stimulus which has released a series of case reports. Cohen and Niska (1980) reported a case of recurrent mania associated with a right brain lesion (subarachnoid haemorrhage), and mention 4 other reports of mania secondary to localized cerebral lesions all of which were in the right brain. They mention Dalen's (1965) suggestion that cerebral damage may provide an alternative to hereditary predisposition in the aetiology of mania. More recent reports include those by Cummings and Mendez (1984) and 
Stasiek and Zetin (1985). Barczak et al. (1988) have reported two cases, and Gillig et al. (1988) and Gross and Herridge (1988) each one other.

Two further cases are added here. The first suggests that cerebral damage may alter the time of the onset of a genetic predisposition to mania.

(i) A 13-year-old boy was referred to a psychiatric facility for the management of persistent and increasing signs of hypomania. He revealed marked motor restlessness, pressure of talk with very marked sexual and salacious overtones, and a preoccupation with his own ideas to the exclusion of the concerns of others. A year before admission he had been admitted to a neurosurgical service for exploration of a left fronto temporal mass on CT scan following signs of an acute rise in intracranial pressure. But all signs of the mass had resolved without treatment. The hypomania appeared some two months before admission in what had been otherwise a year of rehabilitation to school. In the psychiatric unit signs of a left hemiparesis became evident and eventually a lymphoma deep in the right brain was diagnosed. The boy's father and paternal grandmother suffered manic-depressive disorder.

(ii) A 60-year-old man of impeccable background suddenly abandoned the family business and took to driving at great speed in the pursuit of various pleasures. His gross and offensive sexual behaviour in public led to his admission to a psychiatric facility where a mass deep in the right hemisphere was discovered. This too proved to be a lymphoma. (This case was seen by courtesy of Professor B. Blackwell).

While it may be argued that all these cases with right brain lesions might be refuted by counter examples from elsewhere in the brain, and that mass lesions in the right brain do not invariably lead to hypomanic presentation, they are sufficiently suggestive to indicate that a strategy of research, less geared towards making generalizations from large group data and more concerned with detailing the precise circumstances which create the interesting associations, would be helpful in the way that Malamud's (1967) paper drew attention to the association between limbic tumours and schizophrenia.

Hypomanic symptoms in people with epilepsy might be played down at the expense of other diagnoses, in particular, the hyperkinetic syndrome in epileptic children. Originally described by Kramer and Pollnow (1932) as an extreme form of overactivity in children with brain damage or epilepsy, it was described in classic detail in epileptic children by Ounsted (1955) and in cerebral palsy by Ingram (1956). Its appearance in children subsequent to chorea had been mentioned by Winnicott (1931). Although these papers spawned, through Strauss and Lathinen (1947) and Bradley (1942) the vexatious concept of the overactive child, the central issue, of a small subset of epileptic children who display extreme hyperkinesis is well-known to all paediatric neurologists. This type of disorder abates with age and indeed may give rise later to depression and slowing up (ixophrenia). At the time of its original description, child psychiatry was extensively influenced by psychoanalytic concepts according to which young children were precluded from a diagnosis of depression (and hence of manic disorder) because their 
superego was not sufficiently developed. Depression in childhood is now extensively acknowledged (Rutter and Garmezy, 1983) and mania has been described and reviewed by Weinberg and Brumback (1976). The phenomenological similarity between childhood mania and hyperkinesis is compelling (Table 2).

Were childhood hyperkinesis of the severe type to be viewed as a hypomania, we would have, in the lesion-based temporal lobe epilepsies of childhood, a potentially powerful heuristic model for exploring brain behavioural correlates and perhaps a better grasp of the changes in the symptoms of mood-related disorder that occur with development. However, apparent "paradoxical" effects of drugs occur where amphetamines may switch the mood to profound depression (Ounsted, 1955) and phenobarbitone elevate the excitement substantially. There is variability in the severity of such cases but among those given below at least the term mixed affective state might be more appropriate than what is available in the child part of DSM III.

\section{Patient 139909}

He was born in 1974, the middle of 3 boys of intelligent middle class parents. Birth and early development were normal until 21 months when he was discovered convulsing in bed 30 minutes after being put down. He was febrile with a throat infection. Another fever-induced brief seizure occurred at 3 years. Psychomotor attacks began at 4 years 3 months, when in a shop, his face clouded over, he felt "funny, sleepy and had a headache". Seizures later included falling unconscious to the ground. They were unresponsive to valproate but remitted for a year with carbamazepine, then recurred. When admitted to a child psychiatric facility, he experienced many psychomotor attacks and his low mood, anergia, phobia, and social ineptitude were very evident. He remarked "I think that the part of my brain that has fits is the part where my mind is". EEGs suggested a right temporal focus but were inconclusive. Initial scans were negative. After a year of negotiation and treatment failure with increasingly variable swings of mood, parents agreed to consider neurosurgery. Tests in Oxford revealed a lesion of the right temporal pole which proved to be granulomatous tissue and also MTS.

This boy's mood-related disorder was difficult to define but appeared to be predominantly depressive though interrupted at times with periods of excitability, activity, disinhibition and restlessness.

In the next case a more florid hyperkinesia-or hypomania-was attributed to the poverty of his relationship with his mother. It is interesting that this was regarded as an acceptable explanation rather than that his awful behaviour had spoilt their relationship.

\section{Patient 116332}

His unmarried mother suffered pre-eclampsic toxaemia before his birth in 1978. Birth weight was $6 \mathrm{lb} 1 \mathrm{oz}$ and in the special care baby unit two seizures were described. After leaving hospital his mother found him hard to feed, hard to manage and very wakeful. As mother's relationship with him broke down, care was shared with his maternal grandmother. From the time he started to walk, he was regarded as overactive, distractable, oppositional, bad-tempered. In early childhood 
TABLE 2. A contrast/comparison of diagnostic criteria for childhood mania and attention deficit disorder

\section{Childhood Mania}

The presence of either or both symptoms 1 and 2, and three or more of the remaining 6 symptoms (3-8)

(1) Euphoria

(a) Denial of problems or illness

(b) Inappropriate feelings of well-being;

Inappropriate cheerfulness;

Giddiness and silliness

(2) Irritability and/or agitation (particularly belligerence, destructiveness, and antisocial behaviour)

(3) Hyperactivity, "motor driven", intrusiveness

(4) Push of speech (may become unintelligible), garrulousness

(5) Flight of ideas

(6) Grandiosity (may be delusional)

(7) Sleep disturbance (decreased sleep and unusual sleep pattern)

(8) Distractability (short attention span)

Attention Deficit Disorder

A. Inattention. At least 3 of the following

(1) often fails to finish things he or she starts

(2) often doesn't seem to listen

(3) easily distracted

(4) has difficulty concentrating on schoolwork or other tasks requiring sustained attention

(5) has difficulty sticking to a play activity

B. Impulsivity. At least 3 of the following:

(1) often acts before thinking

(2) shifts excessively from one activity to another

(3) has difficulty organizing work (this not being due to cognitive impairment)

(4) needs a lot of supervision

(5) frequently calls out in class

(6) has difficulty awaiting turn in games or group situations

C. Hyperactivity. At least 2 of the following:

(1) excessively runs about or climbs on things

(2) has difficulty sitting still or fidgets excessively

(3) has difficulty staying seated

(4) moves about excessively during sleep

(5) is always "on the go" or acts as if "driven by a motor"

(Taken from DSM III (American Psychiatric Association, 1980) 
"attacks" which were attributed to breath holding were described. By 1985 mother reported to a neurologist that "petit mal" attacks had been occurring for the last year in association with a worsening behavioural problem. No abnormality was seen in his EEG. Social workers concerned about child abuse had given charge of him to his grandmother. Behavioural management by psychologists was attempted but failed. Psychiatric advice was sought.

In the presence of his mother, he was wildly distractable, endlessly and dangerously restless, frantic, noisy, and disinhibited. These traits were reduced in her absence and he could be quieted. He showed high levels of anxiety. His attacks were clearly psychomotor in type and there was an aura and mumbling of gibberish.

His EEGs showed a left temporal focus. His WISC scores were V.92, P.85. He was left-handed. Scans revealed a deep lesion in the mesial aspect of the left temporal lobe. After several weeks of psychological preparation of mother and child, this was removed in May 1986 without sequelae. It was an oligodendroglioma. Rehabilitation was in the psychiatric unit for 3 weeks when he was returned to the care of his mother. By September he and his mother sat quietly for an hour during a revisit to the unit; they seemed to be enjoying their relationship.

\section{Patient 157014}

The fourth of 4 siblings born at term in 1975. His birth and development were normal until a brief fit with fever at 9 months. At 11 months, another convulsion lasted for over an hour and led to some developmental regression. He developed with an early tendency to prefer the left hand. Psychomotor attacks began at 2 years 6 months and were markedly vegetative in form with vomiting at the onset of some attacks and urination with others. In the prodromal period he would sometimes become remarkably tranquil, inert, silent; or else his energy would become even more than usual with flitting attention, distractability, restlessness. His stable mental state, however, was one of pervasive sadness despite his overactivity.

He was sexually, markedly inappropriate making direct and frank sexual advances to nurses.

EEGs showed right-sided onset and emphasis in his attacks and scans confirmed right-sided atrophy. Psychological tests on WISC showed V.74, P.57. No operation is possible.

Voeller (1986) describes a Right Hemisphere Deficit Syndrome in children who showed, for the most part, considerable deficits in performance skills compared to verbal skills, and 14 of the 15 subjects were reported to be "hyperactive" and showed Attention Deficit Disorder, half of them having received medication. They appeared to have great problems with affective cues.

\section{Case 141161}

Born in 1975, the first of 2 children. Normal birth and early development. He suffered mild measles and rubella aged 4 . There were no problems before the onset of epilepsy in November 1982 heralded by a grand mal seizure followed a week later by another and the subsequent rapid development of left-sided focal seizures.

He was admitted from a neurological ward to a psychiatric facility in November 1983 with a history of overactivity, disinhibition and irritability, greatly exacerbated for 2 months since the introduction of primidone. On admission he was overactive, over-talkative, fatuous, glib and disinhibited. EEGs revealed a mainly 
right parieto temporal abnormality with secondary generalization. Scans revealed no abnormality.

Psychometric testing revealed VIQ 108 and PIQ 121. Reading age was 7 years 5 months at 8.4 years. Neither seizures nor mood could be adequately controlled. School work was impaired by lack of concentration, seizures, and behavioural problems. A diagnosis of viral encephalopathy was entertained but could not be proved. Epilepsy continued, the EEG abnormalities generalized, cognitive deterioration ensued and his mood disorder increased with lability, irritability and dysphoria. As his illness progressed his IQs fell: VIQ from 108 to 85 (23 points) and PIQ from 121 to 82 (39 points).

When first seen on the neurological wards at 8 years of age he had been regarded as a hyperkinetic child, fascinated by water, with considerable overactivity, restless, showing marked "attention deficit" and careless, dangerous, play. Regarding his disorder as hypomanic induced by organic cerebral dysfunction is an important reformulation in keeping with the development of mood lability and depressive episodes later.

\section{Relevant Studies in the Falconer Series}

\section{(a) Affective Disorder}

Murray Falconer performed his first temporal lobectomy for epilepsy in 1951. Initially patients came to operation largely via the psychiatrist epileptologists, Desmond Pond and Denis Hill, and spent several weeks preand post-operatively in the psychiatric wards. All the patient clerking and all the research assistants on the unit were psychiatrists. Some patients came via other routes often fortuitously or through special pleading. Many research papers sprang immediately from the enterprise and by 1957 the level of psychiatric morbidity in the first 27 patients operated was very evident (Hill et al., 1957). This is a very important point. It reveals the extreme bias towards working with patients with psychiatric morbidity. But that has proved crucial to the neuropsychiatric research component, that is to say, to make worthwhile statements about the relationship of temporal lobe epilepsy to psychiatric disorder, people with psychiatric disorder and temporal lobe epilepsy must be studied. Of the first 27 cases, however, 18 were regarded as "character disorders" which included very diverse elements of an enduring nature in the personality which were troublesome. In the pre-operative mental state predominantly affective disorder occurred twice in 27 cases.

Post-operatively they noted: (i) improved intellectual functioning, (ii) reduction in aggressiveness, (iii) changes in sexuality, (iv) increased warmth in relationships. These have been many times since confirmed. But Hill et al. (1957) also noted (the idea coming from psychoanalysis) a "turning in" of aggressiveness with a tendency to develop depressive mood. This occurred in 11 of 27 patients. ECT was subsequently given to 5 of these 11 . The paranoid character of the illness was also noted. 
Ten years later Taylor (1968) was influenced, not by a psychoanalytic, but by a sociological perspective. Were patients better off for their surgery? Mental state was a dependent variable classed as tightly as possible. Depression was not a major category in that analysis and more than one category could be used for a patient. About a quarter of the 100 patients had shown depressive features at some time before operation. Post-operative depression was most flamboyant in the immediate post-operative period, usually in people prone to depression. About one-third of the neurotic disorders improved after surgery, but many patients were "depressed" from time to time throughout clinical follow-up. Their mental state sometimes did and sometimes did not affect their work, their lives, and the worthwhileness of surgery. Very poor pre-operative social functioning was unlikely to improve after surgery in adults. Much of the improvement in social functioning is associated with stopping the epilepsy. Social adjustment is a much better basis for judgement than mental state for the purpose of calculating the general benefit of surgery. Significant differences in social adjustment occur between different groups of patients with various small tumours encountered in the resected lobes (Taylor and Marsh, 1977a). The poorest social adjustment pre-operatively was in the group with gangliogliomas and solid angiomas; astrocytomas and oligodendrogliomas were more often associated with marked improvement in adjustment after surgery though late morbidity may supervene.

\section{(b) Suicide}

In keeping with the severe psychopathology, the series had a high rate of suicide. Suicide attempts are one of 8 features, of which 4 are required for a diagnosis of a major depressive episode under DSM III criteria. The notion that attempting suicide is, of itself, suggestive of depressed affect is not supported by actual studies of attempted suicides (Hawton et al., 1982), even though many completed suicides have a history of previous attempts. In case the operation played a part in that mortality, we studied all the deaths (Taylor and Marsh, 1977b). All 193 patients operated before 1970 were studied, giving a 5-year follow-up period at least. There were 37 deaths, including a minimum of 9 and possibly 11 suicides. Three impulsive suicides occurred under the age of 20 but all other suicides and probable suicides occurred in the decade $30-40$ years of age, 5 suicides occurred in the first 2 post-operative years (see Fig. 1).

Studies of suicide in the general population reveal that social isolation, social mobility, divorced and single status, ageing, and many varieties of serious illness and brain disease are conducive to suicide. So that elevated rates of suicide among certain people with epilepsy are consistent with these characteristics and do not necessarily suggest that current affective disorder is the only factor. Suicide is more impulsive in younger persons whether epileptic or not. Barraclough (1981) concluded that people with epilepsy had a fivefold risk of suicide over the population at large. Patients with temporal lobe epilepsy showed rates up to 25 times, whereas those accepted 
SURVIVAL AFTER TEMPORAL LOBECTOMY SHOWING AGE AT OPERATION AND DEATH

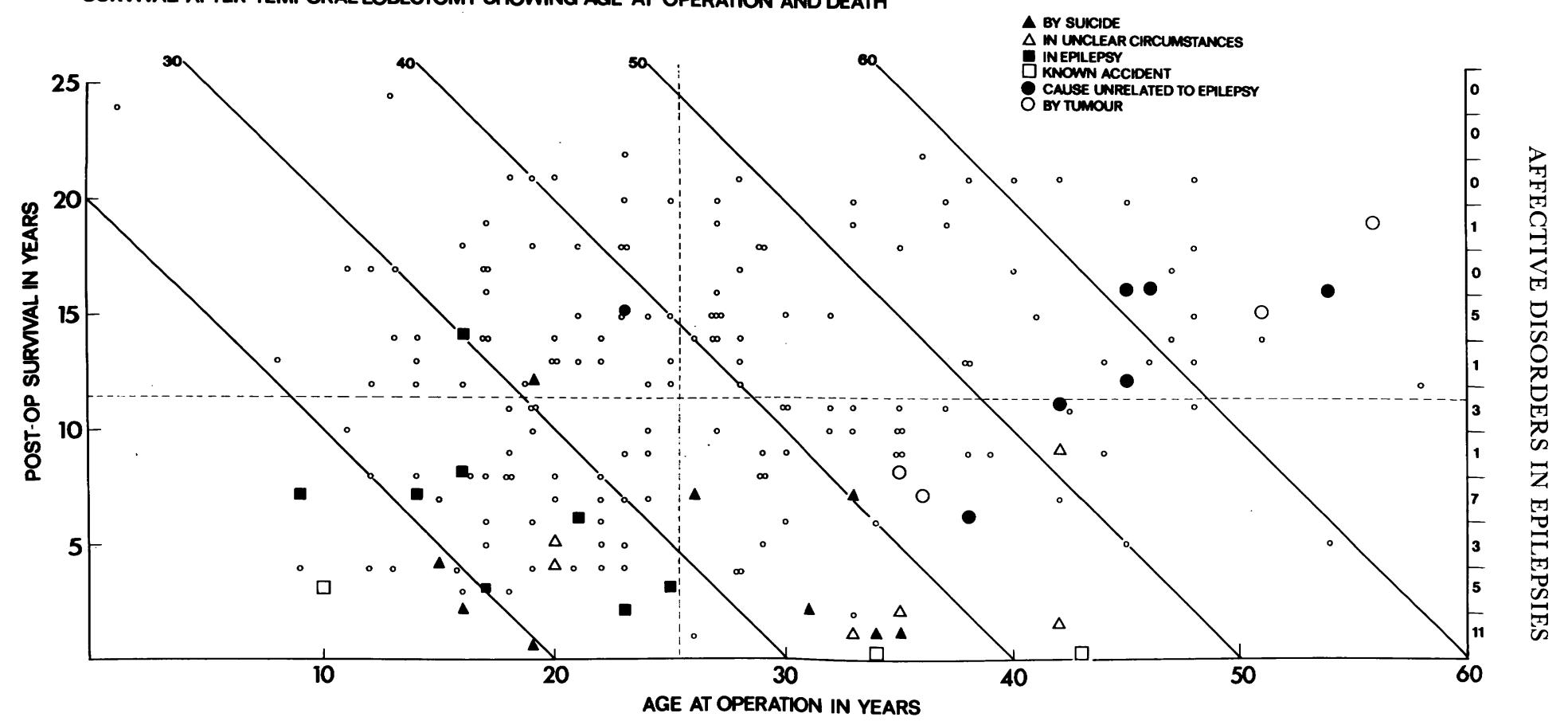

Fig. 1. Timing of suicide after temporal lobectomy. Comparison with other causes of death. (From Taylor and Marsh, 1977b). 
for life insurance only 2.5 times. In samples of people with epilepsy, suicide attempts and completed suicides will vary markedly with the age and sex compositions of the samples and with their degree of social and psychological incapacity.

The study thus confirmed what is known about the characteristics of suicide and reveals no special features related to the epilepsy or the surgery except that the decade of highest suicide risk was a decade younger than in the general population.

\section{(c) Lateralisation of lesion and operation}

There were occasional glimpses of effects-low extraversion in left-operated males (Taylor and Marsh, 1979), schizophrenia in left-operated, lefthanded, late onset epilepsy, females (Taylor, 1975), which have been suggestive of the interest and benefit of left versus right analysis and male versus female analysis.

There was an early indication (Taylor, 1968) of a tendency for "neurosis" to be diagnosed in patients who later had right operations and psychopathy in those who had left operations. Recently (Taylor and Lochery, 1987) have shown that hemisphere-related issues are involved in aura complexity. These are potentially interesting dichotomies because they are clinically relevant. But the more intriguing effects demand the most convoluted analyses and there is much more to be learned.

TABLE 3. Emotional and psychological effects of lateralized brain damage-composite accounts

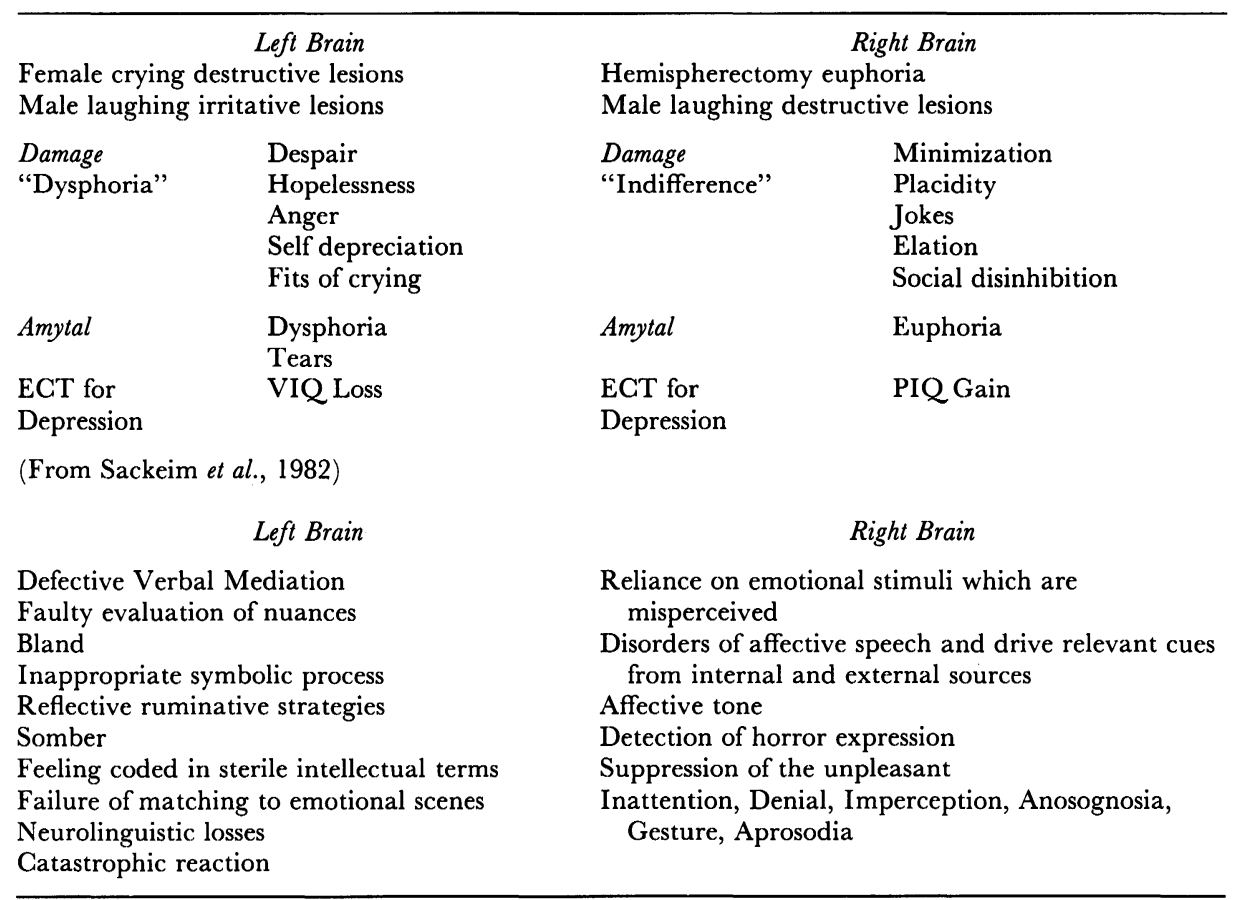

(From Bear and Fedio, 1977; Fedio and Martin, 1983; Sackheim et al., 1982) 
Lateralization effects are unlikely to be consistent as between the sexes and over development. Early life brain lesions may distort normal cerebral organization or else produce behavioural disruptions more characteristic of a general, rather than a specific, brain dysfunction. Tabulations are given drawn from important and suggestive work by Fedio and Martin (1983), Bear and Fedio (1977) and from Sackheim et al. (1982).

Finally, before becoming too enamoured of the "new" dichotomy, we might reflect upon its very long history and its vicissitudes (Harrington, 1985).

\section{Summary}

Does the study of affective disorder in epilepsy prove interesting?

(a) Illuminating mood disorders?

There may be tendencies towards depression or mania with lateralized brain dysfunction though the precise relationship will probably vary between the sexes and with whether the lesion is more irritative than destructive, or vice versa, and the timing of its origin in development. Probably the ordinary cerebral systems regulating mood would be those concerned but these may be damaged and respond differently neurochemically.

(b) Quality or quantity?

Affective disorder in people with epilepsy has been little studied and epilepsy in people with affective disorder largely excludes them from studies. Such studies as there are suggest that rates of affective disorder are increased but not beyond the levels in similar brain disorders such as multiple sclerosis (Schiffer and Babigian, 1984; Rabins et al., 1986). The form of the depressive illness may have an "organic" flavour. Suicide rates are high, not necessarily because of affective disorders alone, but because of the aggregation of many suicide factors in some people with epilepsy.

(c) The subset of persons particularly prone are those who conform most to the sorts of criteria generally associated with depression and these aggregate in people with epilepsy. The "organic" factor, other than "brain damage", is elusive but evidence is supportive of a relationship between deep right brain lesions and hypomania. Hypomania may be a more heuristic description of the "organic hyperkinetic syndrome" and this may suggest structural damage to non-dominant systems as does organic mania. But early life lesions may disrupt dominance relationships.

(d) Neuropsychiatry and Behavioural Neurology offer a new possibility for profitable and beneficial resynthesis. Careful attention deserves to be given to terminologies which appear to be shared but which may have become differently applied between the two disciplines. 


\section{References}

American Psychiatric Association (1980). "Quick Reference to the Diagnostic Criteria from Diagnostic and Statistical Manual of Mental Disorders", Third Edition. Washington, D.C., APA.

Barczak, P. Edmunds, E. and Betts, T. (1988). Hypomania following complex partial scizures. British Gournal of Psychiatry, 152, 137-139.

Barraclough, B. (1981). Suicide and epilepsy. In "Epilepsy and Psychiatry" (Eds E. H. Reynolds and M. R. Trimble). Churchill Livingstone, Edinburgh.

Bear, D. and Fedio, P. (1977). Quantitative analysis of interictal behaviour in temporal lobe cpilepsy. Archives of Neurology, 34, 454-467.

Bradley, C. B. (1942). "Schizophrenia in Childhood". New York.

Cohen, M. R. and Niska, R. W. (1980). Localised right cerebral hemisphere dysfunction and recurrent mania. American Journal of Psychiatry, 137 (7), 847-848.

Cummings, J. L. and Mendez, M. F. (1984). Secondary mania with focal cerebrovascular lesions. American Fournal of Psychiatry, 141, 1084-1087.

Dalen, P. (1965). Family history, the electroencephalogram, and perinatal factors in manic conditions. Acta Psychiatrica Scandinavica, 41, 527-563.

D'Elia, G. and Perris, C. (1973). Cerebral functional dominance and depression. Acta Psychiatrica Scandinavica, 49, 191-197.

Dodrill, C. B., Beier, R., Kasparick, M., Tacke, I., Tacke, U. and Tan, S.-Y. (1984a). Psychosocial problems in adults with epilepsy: comparison of findings from four countries. Epilepsia, 25 (2), 176-183.

Dodrill, C. B., Breyer, D. N., Diamond, M. B., Dubinsky, B. L. and Geary, B. B. (1984b). Psychosocial problems among adults with epilepsy. Epilepsia, 25 (2), 168-175.

Fedio, P. and Martin, A. (1983). Ideative-emotive behavioral characteristics of patients following left or right temporal lobectomy. Epilepsia, 24 (Suppl. 2), S117-S130.

Flor-Henry, P. (1969). Psychosis and temporal lobe epilepsy -A controlled investigation. Epilepsia, 10, 363-395.

Flor-Henry, P. (1983a) "Cerebral Basis of Psychopathology". John Wright/PSG Inc. Littleton, Mass.

Flor-Henry, P. (1983b). Functional Hemispheric Asymmetry and Psychopathology. Integrative Psychiatry, $46-59$.

Flor-Henry, P. (1983c). Determinants of psychosis in epilepsy. Laterality and forced normalisation. Biological Psychiatry, 18 (9), 1045-1057.

Flor-Henry, P. (1985a). Psychiatric aspects of ccrebral lateralization. Psychiatric Annals, 15, $429-434$.

Flor-Henry, P. (1985b). Observations, reflections and speculations on the cerebral deter minants of mood and on the bilaterally asymmetrical distributions of the major neurotransmitter systems. In "Pharmacotherapy of Affective Disorders-Theory and Practice" (Eds W. G. Dewhurst and G. B. Baker. Croom Helm, London.

Gillig, P., Sackellares, J. C. and Greenberg, H. S. (1988). Right hemisphere partial complex seizures: mania, hallucinations, and speech disturbances during ictal events. Epilepsia, 29, 26-29.

Goldberg, D. P. (1972). "The Detection of Psychiatric Illness by Questionnaire". Oxford University Press, London.

Gross, R. A. and Herridge, P. (1988). A maniclike illness associated with right frontal arteriovenous malformation. Fournal of Clinical Psychiatry, 49, 119.120.

Harrington, A. (1985). Nineteenth-century ideas on hemisphere differences and "duality of mind". Behavioral and Brain Science, 8, 617-660.

Hawton, K., O'Grady, J., Osborn, M. and Cole, D. (1982). Adolescents who take overdoses: Their characteristics, problems and contacts with helping agencies. British fournal of Psychiatry, 140, 118-123.

Hill, J. D., Pond, D. A., Mitchell, W. and Falconer, M. A. (1957). Personality changes following temporal lobectomy for epilepsy. Journal of Mental Science, 103, 18-27.

Ingram, 'T. T. S. (1956). A characteristic form of over-active behaviour in brain-damaged children. Journal of Mental Science, 102 (248), 550-563. 
Johnstone, E. C., Owens, D. G. C., Frith, C. D. and Calvert, L. M. (1985). Institutionalisation and the outcome of functional psychoses. British Journal of Psychiatry, 146, 36-44.

Kogeorgos, J., Fonagy, P. and Scott, D. F. (1982). Psychiatric symptom patterns of chronic epileptics attending a neurological clinic: a controlled investigation. British Journal of Psychiatry, 140, 236-243.

Kramer, F. and Pollnow, H. (1932). Uber eine hyperkinetische Erkrankung im Kindesalter. Monatsschrift für Psychiatrie und Neurologie, Berlin, 82.

Krauthammer, C. and Klerman, G. L. (1978). Secondary mania. Archives of General Psychiatry, 35, 1333-1339.

Lewis, D. O., Feldman, M., Greene, M. and Martinez-Mustardo, Y. (1984). Psychomotor epileptic symptoms in six patients with bipolar mood disorders. American Journal of Psychiatry, 141, 1583-1586.

Malamud, N. (1967). Psychiatric disorder with intracranial tumours of the limbic system. Archives of Neurology, 17, 113123.

Mendez, M. F., Cummings, J. L. and Benson, D. F. (1986). Depression in epilepsy. Archives of Neurology, 43, 766-770.

Mukherjece, S., Shukla, S. and Rosen, A. (1984). Neurological abnormalities in patients with bipolar disorder. Biological Psychiatry, 19 (3), 337-345.

Ounsted, C. (1955). 'The hyperkinetic syndrome in epileptic children. Lancet, ii, 303-311.

Perini, G. and Mendius, R. (1984). Depression and anxicty in complex partial seizures. The Journal of Nervous and Mental Disease, 172 (5), 287-290.

Pond, D. A. (1957). Psychiatric aspects of epilepsy. Fournal of the Indian Medical Profession, 3, $1441-1451$.

Rabins, P. V., Brooks, B. R., O’Donnell, P., Pearlson, G. D., Moberg, P., Jubelt, B., Coyle, P., Dalos, N. and Folstein, M.F. (1986). Structural brain correlates of emotional disorder in multiple sclerosis. Brain, 109, 585-597.

Rey, H., Pond, D. A. and Evans, C. (1949). Clinical and electroencephalographic studies of temporal lobe function. Proceedings of Royal Society of Medicine, 42, 891-904.

Robertson, M. M. and Trimble, M. R. (1983). Depressive illness in patients with epilepsy: A review. Epilepsia, 24 (Suppl. 2), S109-S116.

Rutter, M. and Garmezy, N. (1983). Developmental Psychopathology. In "Handbook of Child Psychology" (Ed. P. H. Mussen). Fourth Edition. Volume IV, 776-911.

Sackheim, H. A., Greenberg, M. S., Weiman, A. L., Gur, R. C., Hungerbuhler, J. P. and Geschwind, N. (1982). Hemispheric asymmetry in the expression of positive and negative emotions. Archives of Neurology, 39, 210-218.

Schiffer, R. B. and Babigian, H. M. (1984). Behavioral disorders in multiple sclerosis, temporal lobe epilepsy, and amyotrophic lateral sclerosis. Archives of Neurology, 41, 10671069 .

Schmale, A. H. (1958). Relationship of Separation and Depression to Disease. Psychosomatic Medicine, 20, 259-277.

Scott, D. F. (1985). Left and right cerebral hemisphere differences in the occurrence of epilepsy. British Journal of Medical Psychology, 58, 189-192.

Slater, E. (1936). The inheritance of manic-depressive insanity. Proceedings of the Royal Society of Medicine, 29, 981.

Stasiek, M. A. and Zetin, M. (1985). Organic manic disorders. Psychosomatics, 26, 394-402.

Strauss, A. A. and Lathinen, L. E. (1947). "Psychopathology and Education of the Braininjured Child". New York.

Taylor, D. C. (1968). The outcome of temporal lobectomy for epilepsy. MI) Thesis, University of London.

Taylor, D. C. (1972). Mental state and temporal lobe epilepsy. Epilepsia, 13, 727-765.

Taylor, D. C. (1975). Factors influencing the occurrence of schizophrenia-likc psychosis in patients with temporal lobe epilepsy. Psychological Medicine, 5, 249-254.

Taylor, D. C. (1981). Brain lesions, surgery, seizures and mental symptoms. In "Epilepsy and Psychiatry" (Eds E. H. Reynolds and M. R. Trimble). Churchill Livingstone, Edinburgh.

Taylor, D. C. and Lochery, M. (1987). Temporal lobe epilepsy: origin and significance of simple and complex auras. Fournal of Neurology, Neurosurgery and Psychiatry, 50, 673-681. 
Taylor, D. C. and Marsh, S. (1977a). Neuropathology and social pathology: The effects of small lesions in the temporal lobe. In "Tegretol in Epilepsy". Proceedings of an International Meeting. Geigy Pharmaceuticals, Macclesfield.

Taylor, D. C. and Marsh, S. (1977b). Implications of long-term follow-up studies in epilepsy: with a note on the cause of death. In "Epilepsy, The Eighth International Symposium", (Ed. J. K. Penry). Raven Press, New York.

Taylor, D. C. and Marsh, S. (1979). The influence of sex and side of operation on personality questionnaire responses after temporal lobectomy. In "Hemisphere Asymmetries of Function in Psychopathology" (Eds J. Gruzeller and P. Flor-Henry). Elsevier NorthHolland Biomedical Press, Amsterdam.

Trimble, M. R. and Perez, M. M. (1980). Quantification of psychopathology in adult patients with epilepsy. In "Epilepsy and Behaviour, 1979: Proceedings of Wopsassepy I" (Eds B. M. Kulig, H. Meinhardi and G. Stores). Swets and Zeitlingerbr, Lisse.

Voeller, K. K. S. (1986). Right-hemisphere deficit syndrome in children. American fournal of Psychiatry, 143, 1004-1009.

Weinberg, W. A. and Brumback (1976). Mania in Childhood. American Journal of Disease of Children, 130, 380-385.

Winnicott, D. W. (1931). "Clinical Notes on Disorders of Childhood". London.

Woods, B. T., Kinney, D. K. and Yurgelun-Todd, D. (1986). Neurologic abnormalities in schizophrenic patients and their families. Archives of General Psychiatry, 43, 657-663. 


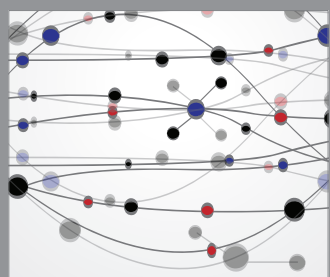

The Scientific World Journal
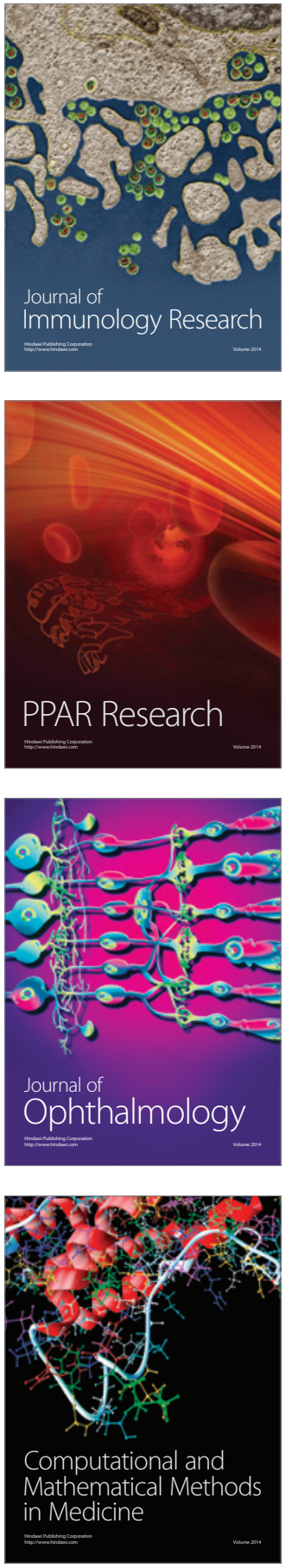

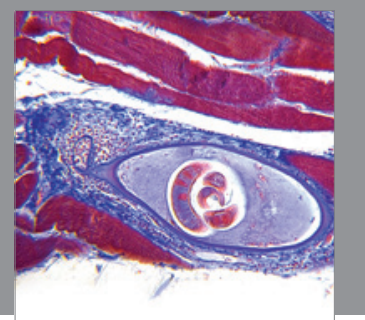

Gastroenterology

Research and Practice
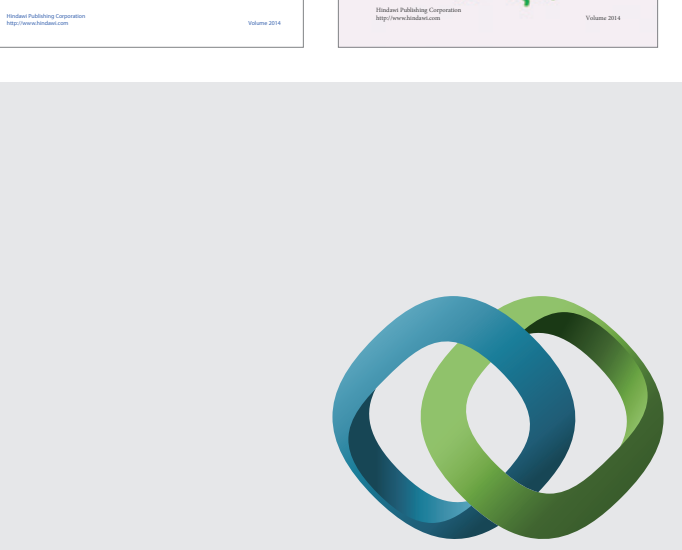

\section{Hindawi}

Submit your manuscripts at

http://www.hindawi.com
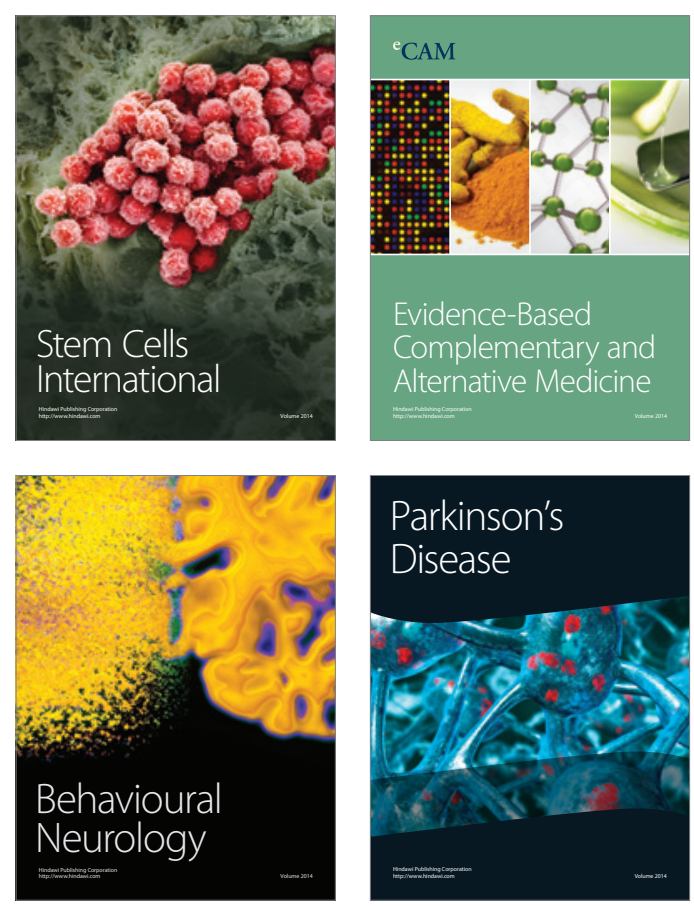

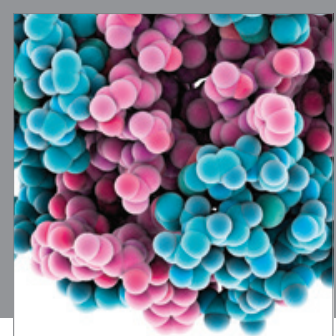

Journal of
Diabetes Research

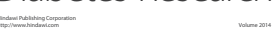

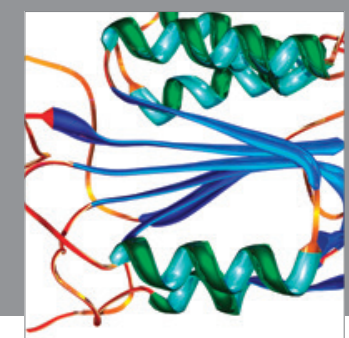

Disease Markers
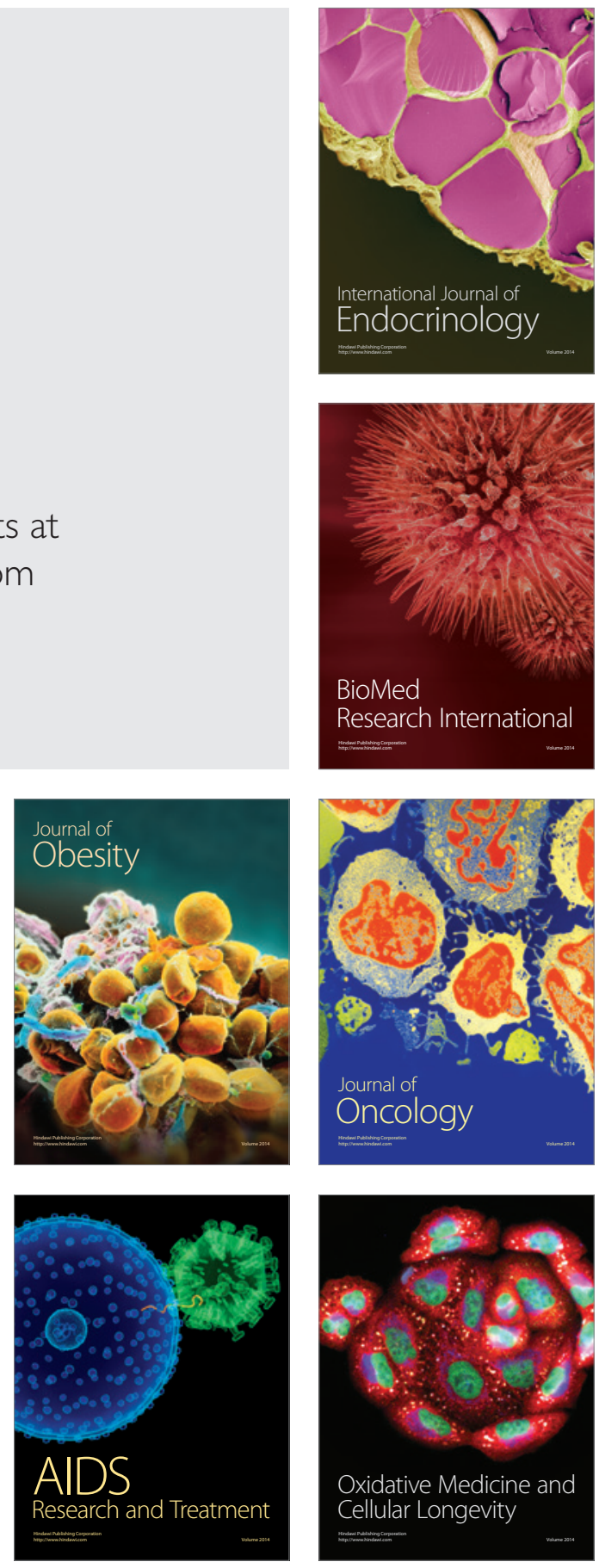